\title{
An enhanced expression of hypothalamic neuronal nitric oxide synthase in a rat model of simulated transport stress
}

\author{
Jia Wang, Jiao Li, Mingyuan Yu, Yuying Wang and Yunfei Ma* (D)
}

\begin{abstract}
Background: Transport stress not only causes physiological changes but also induces behavioral responses, including anxiety-like and depression-like behavioral responses in animals. The neuronal nitric oxide synthase (nNOS) plays a pivotal role in transport stress. This study aimed to investigate the effects of acute transport stress on the expression of nNOS and the distribution of nNOS-positive neurons in the paraventricular nucleus (PVN) and supraoptic nucleus (SON) of the hypothalamus in rats and to explore the neuroendocrine mechanism of transport stress.

Results: In this study, for the first time, we investigated the effects of transport stress on nitric oxide (NO)-NOS in the hypothalamus. After simulated stress, rats exhibited behavioral changes in the open field test (OFT), increased serum corticosterone (CORT) and norepinephrine (NE) levels, and increased NO content in the hypothalamus. In addition, nNOS expression in the hypothalamic PVN was upregulated, and its distribution was altered in stressed rats compared with that of unstressed rats.
\end{abstract}

Conclusions: Our findings indicate that simulated transport stress increases nNOS expression and alters its distribution in the PVN of the rat hypothalamus.

Keywords: NO, nNOS, Transport stress, Hypothalamic, Paraventricular nucleus, Supraoptic nucleus

\section{Background}

Live animal transport has increased steadily in recent decades. Numerous studies have shown that productive performance, behavioral status, and physiological indicators change after transportation. During transportation, animals are stimulated by a variety of stressors, including capture, vibration, collision, temperature extremes, thirst, and hunger [1]. Superposition of these stressors leads to changes in blood composition, hormones, metabolites, enzymes, and behavior [1, 2]. These changes adversely affect animal health and welfare $[3,4]$. In addition, the influence of stressors on animal physiology and behavior may lead to weight loss, increased mortality, and declined meat and skin quality, resulting in significant economic losses $[5,6]$.

Experimental animals are frequently transported in large quantities to keep up with current developments in

\footnotetext{
* Correspondence: yunfeima@cau.edu.cn; yfmcau@163.com

This study was conducted at China Agricultural University.

College of Veterinary Medicine, China Agricultural University, Beijing 100193, China
}

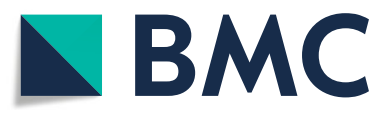

(C) The Author(s). 2019 Open Access This article is distributed under the terms of the Creative Commons Attribution 4.0 International License (http://creativecommons.org/licenses/by/4.0/), which permits unrestricted use, distribution, and reproduction in any medium, provided you give appropriate credit to the original author(s) and the source, provide a link to the Creative Commons license, and indicate if changes were made. The Creative Commons Public Domain Dedication waiver (http://creativecommons.org/publicdomain/zero/1.0/) applies to the data made available in this article, unless otherwise stated. scientific research across a wide array of disciplines. The stress on animals caused by transportation from the breeding base to the research institution may induce adverse effects in each transported animal [7]. Behavior, blood biochemical indexes, physiology, and neurohormones of transported animals all change correspondingly $[2,8,9]$. When animals are stressed, the hypothalamic-pituitary-adrenal (HPA) axis is activated and releases corticotropin-releasing hormone $(\mathrm{CRH})$ from the hypothalamus, which promotes the release of adrenocorticotropic hormone $(\mathrm{ACTH})$ in the anterior pituitary. ACTH activates the release of glucocorticoids from the adrenal cortex, which, in turn, produces negative feedback on the hypothalamus, anterior pituitary, and hippocampus to counteract the effects of stress on the internal environment. Notably, neuronal nitric oxide synthase (nNOS) is expressed in immature and mature neurons [10, 11], astrocytes, cerebral arterial outer membranes, and myocardial cells in rats $[12,13]$. Nitric oxide (NO), which is primarily produced by nNOS in neural tissues $[14,15]$, plays a crucial 
role in the response of these tissues to acute stress. Under stress conditions, NOS regulates sympathetic activation by central $\mathrm{CRH}$ and may affect HPA axis activity. The paraventricular nucleus (PVN) is one of the major nuclei in the hypothalamus, which regulates $\mathrm{NO}$ activity in stress and is one of the most significant brain regions in terms of nNOS expression [16].

Despite abundant evidence that transport stress affects animal behavior and physiological indicators, the effects of transport stress on NO-NOS in the hypothalamus have not yet been explored. In this study, we used a simulated transport stress model to investigate the effects of transport stress on anxiety-like behavior, NO content, and nNOS expression in the brain, as well as the distribution of nNOS-positive neurons in the PVN and supraoptic nucleus $(\mathrm{SON})$ of the hypothalamus in rats. The aims of this study were to explore the unfavorable effects of transport stress on animals, elucidate the neuroendocrine mechanism of transport stress, and formulate effective therapies to prevent and treat transport stress.

\section{Methods}

Animals

We used adult male Sprague Dawley rats (200-220 g, Beijing Vital River Laboratory Animal Technology Co. Ltd., Beijing, China) for all experiments in this study. The rats were housed in cages at a moderate density $(54 \times 39 \times 20$ $\mathrm{cm}, n=3)$ under the following standard laboratory conditions: room temperature $\left(25^{\circ} \mathrm{C} \pm 2{ }^{\circ} \mathrm{C}\right), 12$-h light/dark cycle, $60 \% \pm 5 \%$ humidity, and free access to water and food. Lights were turned on and off at 8:00 a.m. and 8:00 p.m., respectively. The protocols for animal use and experimentation were in accordance with the Beijing Laboratory Animal Welfare and Ethics guidelines. Additionally, all work involving animal research was approved by the Beijing Administration Committee of Laboratory Animals and was in accordance with the China Agricultural University (CAU) Laboratory Animal Welfare and Animal Experimental Ethical Committee guidelines. Every effort was made to minimize the suffering and number of rats used.

\section{Rat model of simulated transport stress}

A rat model of simulated transport stress was established as previously described [17], with a slight modification. The 24 rats used for this model were housed under standard laboratory conditions for 7 days and were randomly divided on the eighth day into a control group $(n=12)$ and a transport stress (TS) group $(n=12)$ based on the random number table method. The rats in the TS group were subjected to vibration at $0.1 \mathrm{~g}$ (reactive centrifugal force) on a constant temperature shaker (DHZ-CA, Taicang Co. Ltd., Tianjin, China) from 9:00 a.m. to 11:00 a.m. to simulate transport stress for $2 \mathrm{~h}$.

\section{Behavioral testing}

All rats were subjected to the open field test (OFT) immediately after the simulated transport stress $(n=12$ rats per group). Rats from the stress and control groups were tested simultaneously so that both groups were tested in the same period. On the day of the test, the rats were transported to the testing room. The testing apparatus was an illuminated, soundproofed box $(100 \times 100 \times 50$ $\mathrm{cm})$ with black inner walls. The bottom surface of the box was divided into 25 squares $(15 \times 15 \mathrm{~cm})$. The apparatus was cleaned with $70 \%$ ethanol before testing of each animal. The methodology used for the OFT was the same as that described previously [18]. Each rat was placed onto a corner square of the arena and allowed to explore the open field freely for $5 \mathrm{~min}$ per trial. A camera was installed at the top right of the box to record the rats' activities. The number of squares crossed and the number of rearing episodes (defined as standing on the hindlimbs without touching the wall) were recorded; the sum of these two parameters was used as the total score to evaluate the general activity of the rats.

\section{Collection and processing of tissue samples}

We used a previously described methodology for collection and processing of tissue samples [19]. Six rats in each group were used for molecular biology analysis, and the remaining rats were used for histological analysis. The blood samples were collected $2 \mathrm{~h}$ after the final behavioral test. Six rats from each group were anesthetized with $1 \%$ sodium pentobarbital $(5 \mathrm{mg} / 100 \mathrm{~g}$ body weight) via intraperitoneal injection, exsanguinated via the jugular vein, and then euthanized through neck dislocation. The blood samples were centrifuged at $2000 \times g$ for $10 \mathrm{~min}$ at $4{ }^{\circ} \mathrm{C}$, and then the serum samples were collected and stored at $-20^{\circ} \mathrm{C}$ for the determination of corticosterone (CORT) and norepinephrine (NE) contents. After euthanizing the rats, hypothalamic tissues were removed, frozen in liquid nitrogen, and stored at $-80{ }^{\circ} \mathrm{C}$ for until subsequent measurements of $\mathrm{NO}$ content and nNOS mRNA and protein expression. The other six rats in each group were anesthetized with sodium pentobarbital, perfused transcardially with $200 \mathrm{~mL}$ of 5 - $\mathrm{mM}$ sodium phosphate ( $\mathrm{pH} 7.4$ )-buffered $0.9 \% \quad(\mathrm{w} / \mathrm{v})$ saline (PBS), followed by perfusion with $300 \mathrm{~mL}$ of $4 \%(\mathrm{w} / \mathrm{v})$ formaldehyde in $0.1 \mathrm{M}$ of sodium phosphate buffer $(\mathrm{pH}$ 7.4). The brains were removed, cut into several blocks, and postfixed with the same fixative for 1 day at $4{ }^{\circ} \mathrm{C}$. After cryoprotection with $30 \%(\mathrm{w} / \mathrm{v})$ sucrose in PBS overnight, the blocks were embedded with embedding medium on a freezing microtome at $-20^{\circ} \mathrm{C}$ for $30 \mathrm{~min}$ and were then cut into $30-\mu \mathrm{m}$-thick sections, which were placed in PBS for subsequent immunohistochemical staining. 
Corticosterone (CORT), norepinephrine (NE), and nitric oxide (NO) analysis

The serum levels of CORT were measured using a radioimmunoassay with a Vitek Immune Diagnostic Assay System (Bio-RAD iMark, Berkeley, California, USA) according to the manufacturer's instructions by using a CORT assay kit (HY-10063, Beijing Sino-UK Institute of Biological Technology, Beijing, China). The concentrations of serum NE were detected using an enzyme-linked immunesorbent assay (ELISA) according to the manufacturer's instructions by using a NE assay kit (H096, Nanjing Jiancheng Bioengineering Institute, Nanjing, China). The samples were weighed and then homogenized on ice to detect the content of NO in the hypothalamus. After the solution was centrifuged at $1000 \times g$ for $10 \mathrm{~min}$, the supernatant was collected, and the NO content was detected using the nitric-acid-reductase method according to the manufacturer's instructions using a NO assay kit (A012-1-2, Nanjing Jiancheng Bioengineering Institute, Nanjing, China; $n=12$ rats per group).

\section{RNA isolation and reverse transcription-polymerase chain reaction}

We used the a previously described methodology for RNA isolation and reverse transcription-polymerase chain reaction [19]. Total RNA was isolated using TRIzol reagent (Invitrogen, Carlsbad, CA, USA) in accordance with the manufacturer's protocol, followed by purification using an RNeasy mini kit (Qiagen, Valencia, CA, USA). The quality of the purified RNAs was determined by calculating the ratio of the absorbance at 260 and $280 \mathrm{~nm}$ using a NanoDrop ND-1000 spectrophotometer (NanoDrop Technologies, Wilmington, DE, USA). RNAs were reverse transcribed into cDNA using a FastQuant RT kit (Tiangen Biotech Co. Ltd., Beijing, China). The expression levels of nNOS were quantified using a semiquantitative reverse transcriptionpolymerase chain reaction (RT-PCR). Gene expression was normalized with glyceraldehyde-3-phosphate dehydrogenase (GAPDH) as the internal standard. The primer sequences of $n N O S$ and GAPDH genes are listed as follows: nNOS-forward: 5' -AATGGAGACCCCCCTGAGAAC-3'; nNOS-reverse: $\quad 5$ '-TCCAGGAGGGTGTCCACCGC-3'; GAPDH-forward: $\quad 5^{\prime}$-GAAGGTCATCCATGACAA CTTTG-3'; GAPDH-reverse: 5'-GTCCACCACCCTGT GGTGTAG-3'. The cycling parameters used for amplification were as follows: initial heat denaturation at $95^{\circ} \mathrm{C}$ for $5 \mathrm{~min}$; 30 cycles of $94^{\circ} \mathrm{C}$ for $45 \mathrm{~s}, 55^{\circ} \mathrm{C}$ for $30 \mathrm{~s}$, and $72{ }^{\circ} \mathrm{C}$ for $30 \mathrm{~s}$; and an extension at $72{ }^{\circ} \mathrm{C}$ for $7 \mathrm{~min}(n=6$ rats per group).

\section{Protein extraction and western blotting}

Total protein was extracted using a total protein extraction kit (Biochain, Hayward, CA, USA) and was quantified using a bicinchoninic acid protein assay kit (78,510, Pierce, Rockford, IL, USA). A 10\% separating gel was prepared and consisted of the following: distilled water, $6.1 \mathrm{~mL} ; 30 \%$ acrylamide, $5 \mathrm{~mL}$; $4 \times$ sodium dodecyl sulfate-polyacrylamide gel electrophoresis (DS-PAGE) separating gel buffer, $3.75 \mathrm{~mL} ; 10 \%$ ammonium persulfate, $0.15 \mathrm{~mL}$; and TEMED, $6 \mu \mathrm{L}$. The $10 \%$ separating gel was allowed to solidify for $30 \mathrm{~min}$. A $5 \%$ stacking gel was prepared (distilled water, $3.2 \mathrm{~mL} ; 30 \%$ acrylamide, 0.5 $\mathrm{mL} ; 4 \times$ SDS-PAGE separating gel buffer, $1.25 \mathrm{~mL} ; 10 \%$ ammonium persulfate, $0.05 \mathrm{~mL}$; and TEMED, $5 \mu \mathrm{L}$ ), and allowed to solidify for $30 \mathrm{~min}$. Next, $20 \mu \mathrm{g}$ of protein from each sample was loaded on SDS-PAGE sample loading buffer (P0015; Beyotime Institute of Biotechnology, Jiangsu, China). Subsequently, electrophoresis was performed at $80 \mathrm{~V}$ for $30 \mathrm{~min}$, and was then switched to $120 \mathrm{~V}$ for $90 \mathrm{~min}$. A sponge cushion, filter paper, gel, polyvinylidene fluoride membrane, filter paper, and sponge cushion were placed in the clamp in sequential order and were then placed in $1 \times$ transmembrane buffer at $200 \mathrm{~mA}$ for $120 \mathrm{~min}$. A polyvinylidene fluoride membrane was washed three times with TBST (10 min each time) and was then placed in a 5\% non-fat milk sealing solution, which was placed on a shaking table at room temperature for $2 \mathrm{~h}$. Subsequently, the membranes were probed with a specific rabbit polyclonal antibody against nNOS (1:2500; AB76067, Abcam, Cambridge, MA, USA) overnight at $4{ }^{\circ} \mathrm{C}$. The membranes were then incubated with horseradish peroxidase-conjugated goat antibody against rabbit IgG (1:5000; AP132P, Beijing ComWin Biotech Co., Ltd., Beijing, China) for $1 \mathrm{~h}$ at $37^{\circ} \mathrm{C}$. Blots were normalized using $\beta$-actin antibody (1:5000; 50,201, Kemei Borui Technology Co., Ltd., Beijing, China) to correct for differences in the loading quantity of the protein samples. One milliliter of electrochemiluminescence liquid (WBKLS0100, Millipore, Billerica, MA, USA) was added onto the protein bands, which were imaged using a Tanon chemiluminescence system (5200, Tanon Science Technology Co., Ltd., Shanghai, China). Densitometric values of immunoblot signals were obtained from three separate experiments ( $n=6$ rats per group) using ImageJ (National Institutes of Health, New York, NY, USA) [19].

\section{Immunohistochemical staining}

For immunohistochemical staining, we used a method that has been described previously [19]. Frozen sections were rinsed in PBS and were then incubated in $2 \%$ hydrogen peroxide for $20 \mathrm{~min}$ to remove endogenous peroxidase reactivity. All incubations were performed at room temperature, and the sections were rinsed with PBS containing $0.3 \%$ Triton X-100 (PBS-X). The sections were incubated overnight with a sheep polyclonal antibody against nNOS (1:1000; ab1529, Millipore, Billerica, MA, USA) in PBS-X containing $0.12 \%$ lambda-carrageenan, $0.02 \%$ sodium azide, and $1 \%$ donkey serum (PBS-XCD), and were then incubated for $2 \mathrm{~h}$ with 
biotinylated donkey anti-sheep IgG (1:100; 711,065,147, Jackson, Penn, Lancaster, USA) in PBS-XCD. Subsequently, the sections were incubated in $\mathrm{ABC}$-peroxidase solution (1:100; PK-6102, Vector, Torrance CA, USA) for $30 \mathrm{~min}$, and the bound peroxidase was finally developed to yield a brown reaction product via reaction for 20-30 min with $0.02 \%$ diaminobenzidine-4HCl (DAB; D5637, Sigma Chemical Co, St. Louis, Missouri, USA), and $0.0001 \% \mathrm{H}_{2} \mathrm{O}_{2}$ in $50 \mathrm{mM}$ Tris- $\mathrm{HCl}(\mathrm{pH}=7.6)$. All stained sections were mounted onto gelatinized glass slides, dried, dehydrated in an ethanol series, cleared in xylene, and coverslipped. The same procedure was carried out for the negative control sections, except that the primary antibodies were substituted with PBS. The sections were observed (Fig. 4) under a microscope (Ni-U, Nikon, Japan), and the immunoreactivity intensities of nNOS were determined using Image-Pro plus 6.0 (Media Cybernetics, Bethesda, MD, USA). The cytoarchitectonic areas of hypothalamic PVN and SON were determined using the rat brain atlas [20,21], ( $n=6$ rats per group).

\section{Statistical analysis}

Statistically, no less than six rats in each group were required for statistical significance, and the animal experimental design followed the "3R principle" [17]. All data were analyzed using one-way analysis of variance with
SPSS 17.0 (IBM Inc., Chicago, IL, USA). Before analysis, the normal distribution of all data was verified using the skewed Kurtosis test. All results are presented as the mean \pm SD. Comparisons between the groups were analyzed using a Student's $t$-test. A $P<0.05$ was considered statistically significant $\left({ }^{*} P<0.05,{ }^{* *} P<0.01\right)$.

\section{Results}

\section{Simulated transport-induced stress responses in rats}

Compared with that of the control group, the rats in the TS group showed abnormal behavior-such as loss of interest, higher sensitivity, matted fur, and rough hair-toward the corner of the open field (Fig. 1a and b). The general activity of the rats was measured using the OFT. The total score of the OFT (Fig. 1c) was significantly lower for the TS group than for the control group $(P<0.01)$.

\section{Transport stress enhances CORT and NE content in the rat brain}

The contents of serum CORT and NE in the rats from each group were analyzed (Fig. 2). The results showed that the contents of serum CORT (Fig. 2a) and NE (Fig. 2b) were significantly increased in the TS group $(P<0.05$, respectively) compared with those in the control group.
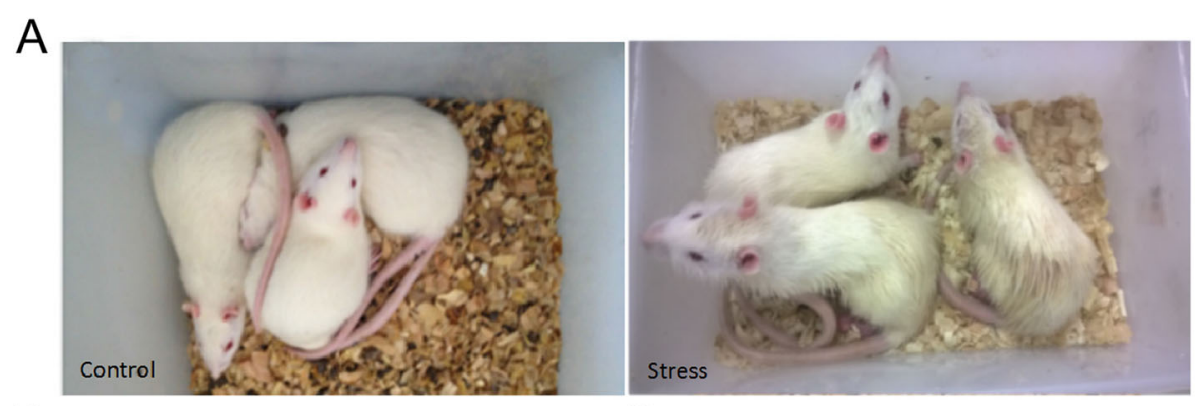

B

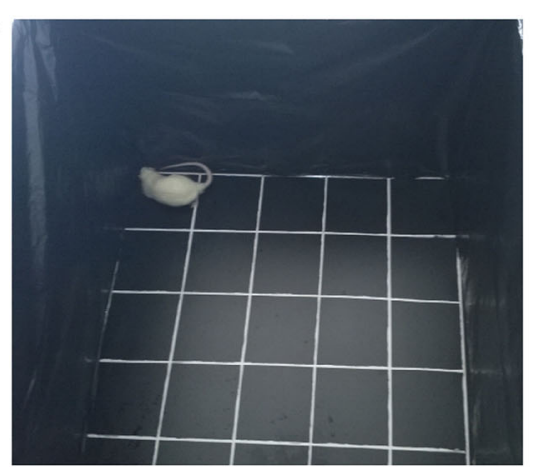

C

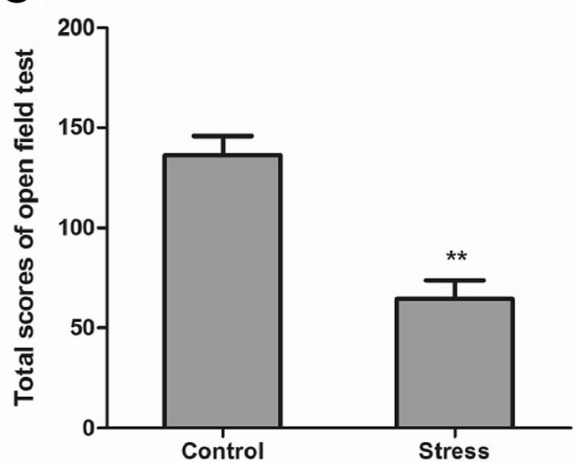

Fig. 1 Effect of simulated transport stress on the behavior of rats according to the open-field test. Control and Stress stand for the control group and simulated transport-stress group, respectively. Effect of simulated transport stress on the behavior of rats (a) (b) and the open-field test scores in each group (c). Data are presented as mean \pm SD ( $n=12$ rats per group). Comparisons between the groups were analyzed using Student's $t-$ tests. ${ }^{* *}$ stands for the comparison between the control group and simulated transport stress group $(P<0.01)$ 

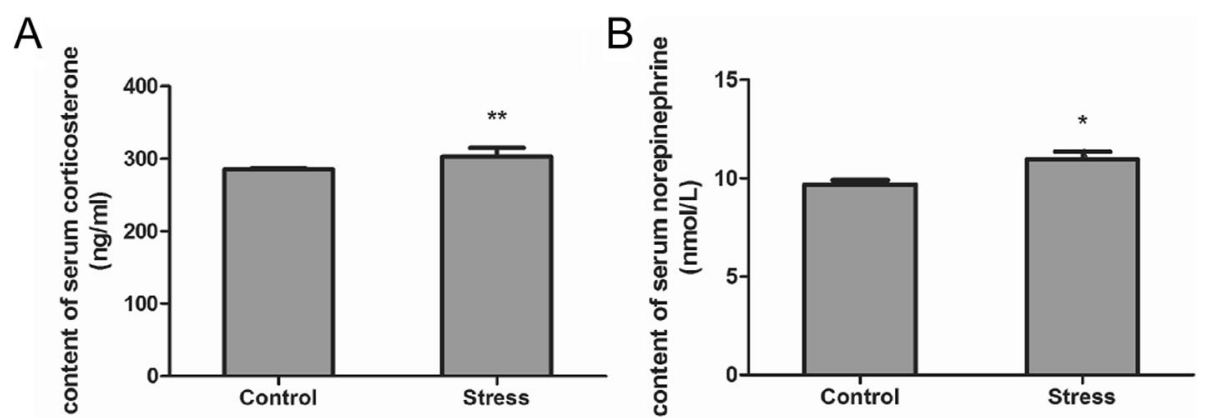

Fig. 2 Effect of simulated transport stress on the content of serum CORT and NE in rats. Control and Stress stand for the control group and simulated transport stress group, respectively. Effect of simulated transport stress on the content of serum CORT (a) and serum NE (b). Data are presented as mean \pm SD ( $n=12$ rats per group). Comparisons between the groups were analyzed using Student's $t$-tests. ${ }^{*}$ stands for the comparison between the control group and simulated transport stress group $(P<0.05)$

Transport stress enhances NO content in the rat brain and nNOS mRNA and protein expression in the

\section{hypothalamus}

Compared with the control group, the $\mathrm{NO}$ content in the brain tissue of the stress group was significantly increased by $49.51 \%$ ( $P=0.006$; Fig. 3a). In terms of RT-PCR, no significant difference was observed in the nNOS mRNA expression between the stress and control groups in the hypothalamus (Fig. 3b). Based on the results of western blotting, the expression of nNOS protein in the stress group was significantly increased by $44.92 \%$, as compared with that of the control group $(P=0.003$; Fig. 3c). These results suggest that stress increases brain NO content and nNOS protein expression.
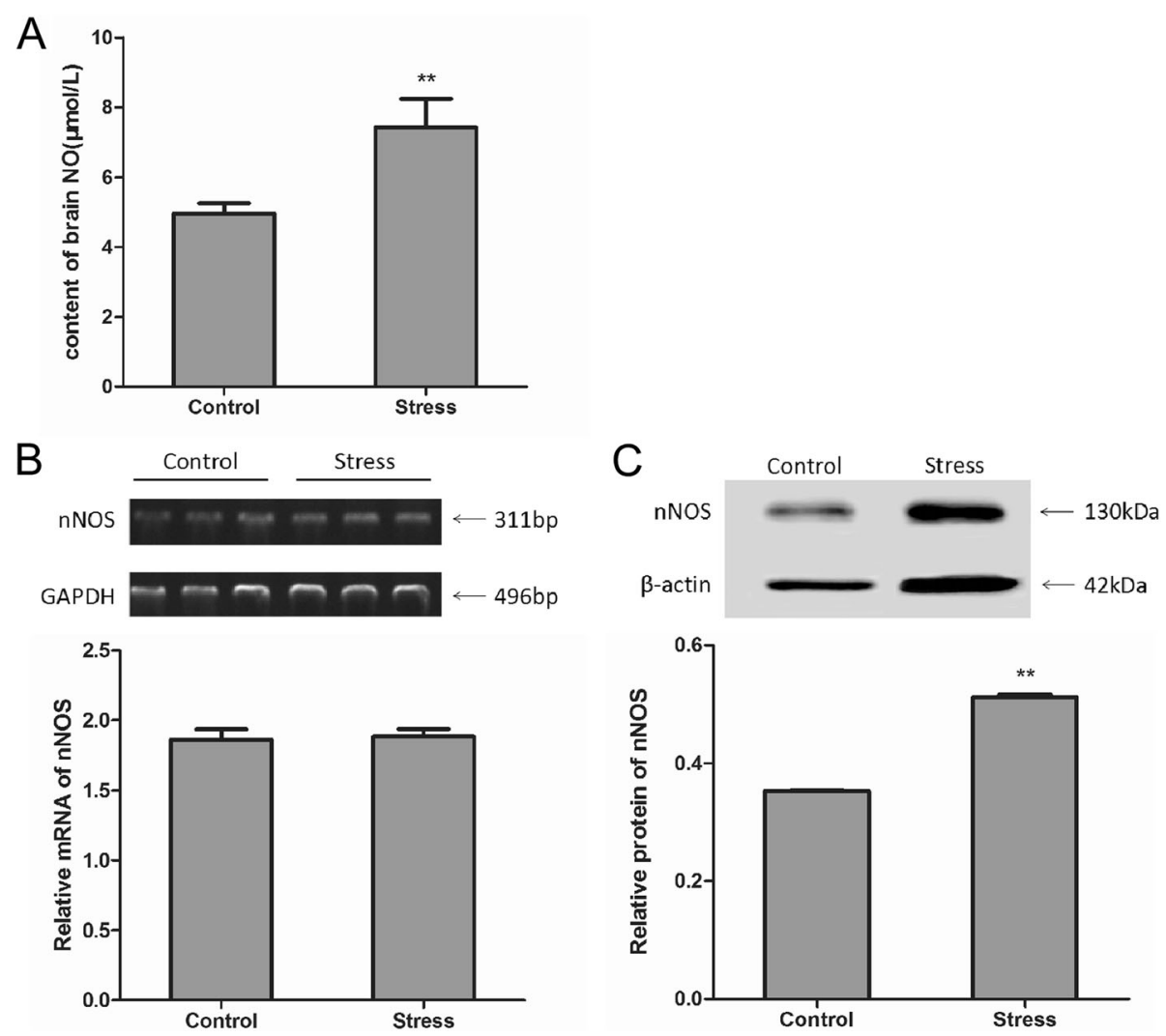

Fig. 3 Effect of simulated transport stress on NO and nNOS levels in rats. Control and Stress stand for the control group and simulated transport stress group, respectively. Effect of simulated transport stress on the NO levels (a) and nNOS levels (b) (c). Data are presented as mean \pm SD $(n=6$ rats per group). Comparisons between the groups were analyzed using Student's $t$-tests. ${ }^{* *}$ stands for the comparison between the control group and simulated transport stress group $(P<0.01)$ 


\section{Distribution of nNOS-positive neurons in the PVN and SON}

The results of immunohistochemistry showed that (Fig. 4) nNOS-immunopositive neurons were mainly distributed in the PVN and SON of the hypothalamus, primarily in the cytoplasm (with less nuclear staining). The PVN can be divided into the anterior, medial, and posterior subregions. The nNOS neurons were expressed more in the medial and anterior regions, and less in the posterior region. In the anterior chamber of the PVN (Paap), nNOS-positive neurons were scattered, and the cell bodies were fusiform, oval and triangular. The medial part of the PVN is further divided into the medial anterior and medial posterior subregions. The medial anterior part consists mainly of the central large cell area (Pamm) of the hypothalamic PVN. The medial posterior part typically consists of the hypothalamic paraventricular ventral area (Pav) and large cell area (Palm) in the lateral nucleus of the hypothalamus. In the medial part of the hypothalamus, nNOS-positive neurons were densely clustered, and the cell bodies were fusiform, oval and triangular. The cell outlines were clear, and the protrusions were apparent with a deep coloration; the interlacing pattern was indicative of a network structure.

We analyzed the number of nNOS-positive cells in the hypothalamus of different treatment groups (Fig. 5). In the Pav + Palm area of the PVN, the number of nNOS- positive cells in the stress group was significantly increased by $22.16 \%(P=0.001)$ compared with that of the control group, whereas no significant differences were observed in terms of the numbers of positive cells between the other subregions of the PVN and SON. The average optical density of nNOS-immunoreactive neurons in the hypothalamus of each rat was further analyzed. Compared with that of the control group, the stress group showed increased nNOS expression in the Paap and Pamm areas of the PVN; however, this difference was not significant. nNOS expression in the ventral region of the PVN and the lateral large cell area (Pav + Palm) were higher than those in the first two regions. nNOS expression in the stress group was significantly increased by $73.47 \%(P=0.001)$, as compared with that of the control group. nNOS expression in the SON was significantly increased by $20.8 \%(P=0.001)$ in the stress group compared with that of the control group.

\section{Discussion}

Animals undergoing long-term transportation will be stimulated by various kinds of stimuli, which will lead to stress, physiological/psychological changes, and even diseases and deaths [22]. Transport stress is a comprehensive stress model, which involves multiple factors [23], such as animal age, gender, transportation distance, and
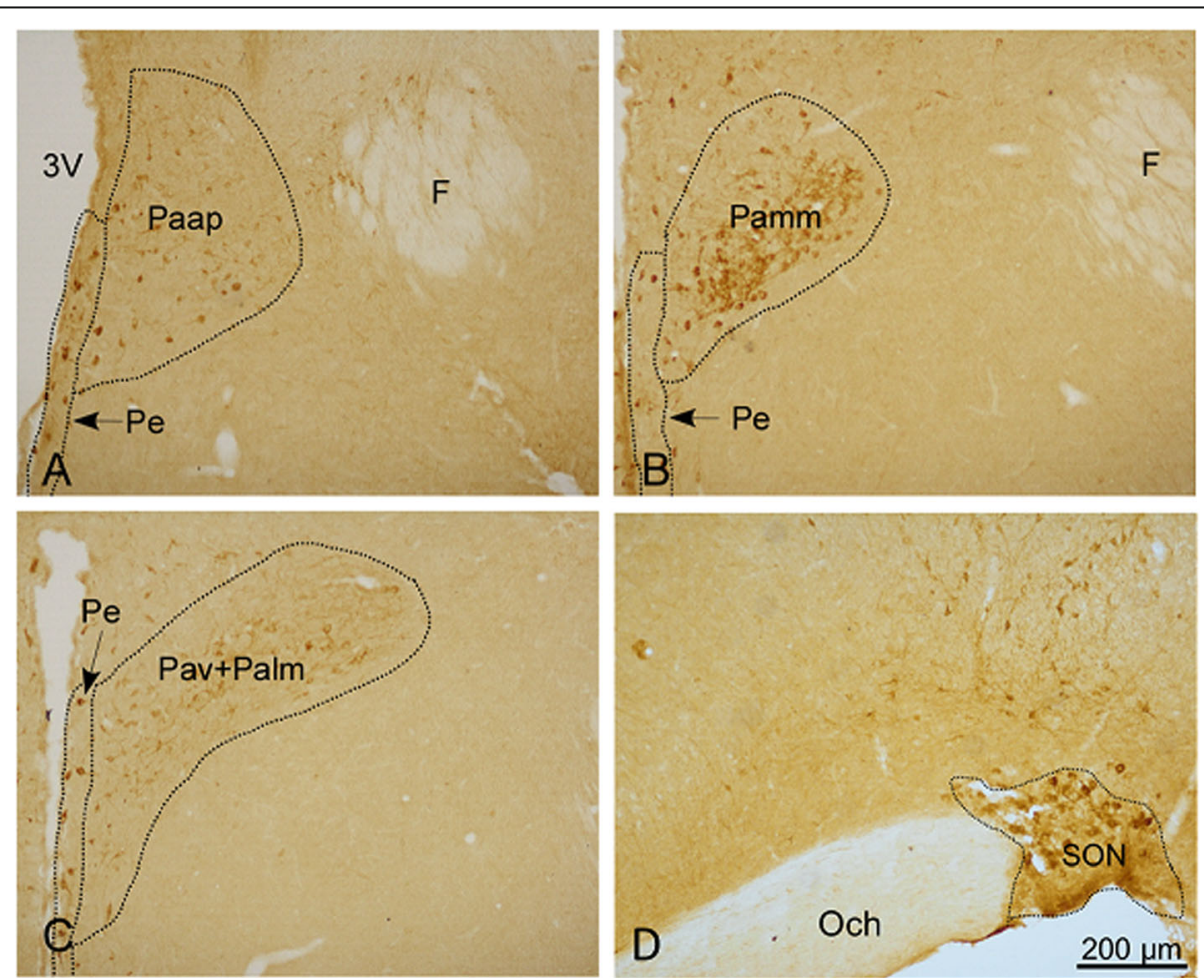

Fig. 4 Effect of simulated transport stress on the distribution of nNOS-positive neurons in the PVN and SON. Control and Stress stand for the control group and simulated transport stress group, respectively. Effect of simulated transport stress on the distribution of nNOS-positive neurons in the Paap (a), Pamm (b), Pav + Palm (c), and SON (d) 

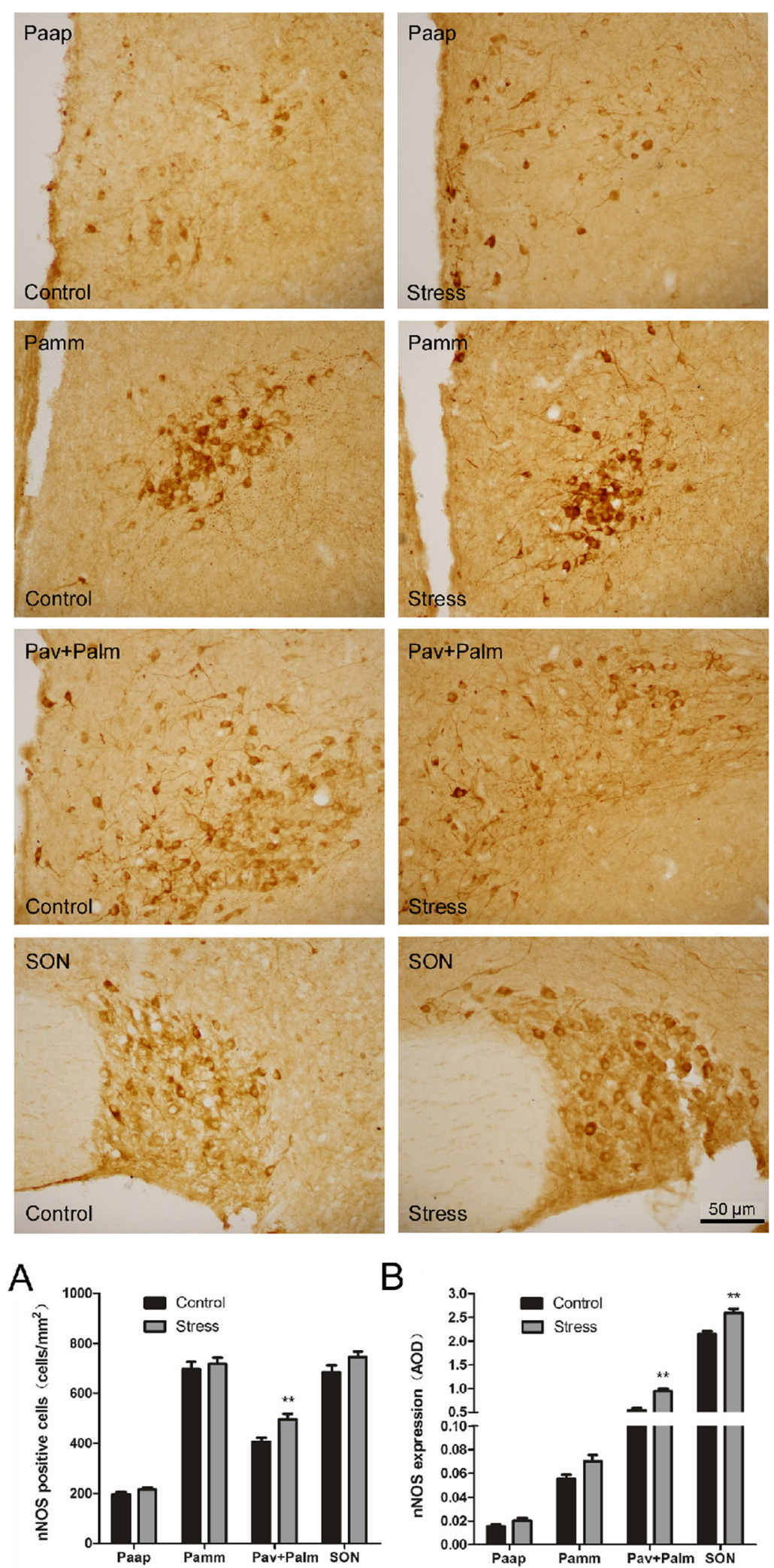

B

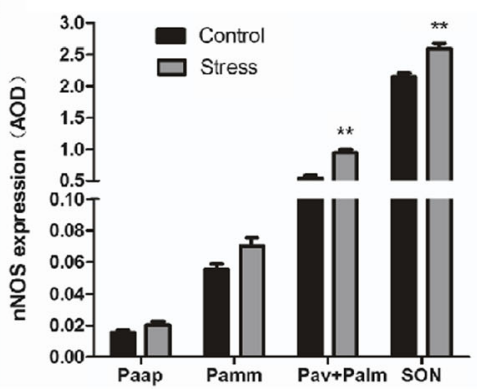

Fig. 5 (See legend on next page.) 
(See figure on previous page.)

Fig. 5 Effect of simulated transport stress on nNOS levels in the hypothalamus of rats. Control and Stress stand for the control group and simulated transport stress group, respectively. Effect of simulated transport stress on nNOS-positive cells (a) and nNOS expression (b). Data are presented as the mean \pm SD ( $n=6$ rats per group). Comparisons between the groups were analyzed using Student's $t$-tests. ${ }^{* *}$ stands for the comparison between the control group and simulated transport stress group $(P<0.01)$

choice of transportation tools. In this study, laboratory animals were subjected on a constant temperature shaker to simulate transport stress. The OFT, as well as serum CORT and NE concentrations, were used to identify whether the model was effective at inducing behavioral and physiological markers of stress. The results showed that the rats in the TS group exhibited lower activity on the OFT and elevated serum CORT. CORT can act as a stress hormone [24, 25]. The OFT is a common method to examine psychological function [26]. In this study, the results of the OFT and the measurement of serum CORT and NE indicated that the transport stress model was successfully established.

The HPA axis is a central control and organ-regulation system that links the central nervous system to the endocrine system. A dysfunction of the HPA axis is related to clinical manifestations of physical and mental illnesses [27]. For example, in severe depression and post-traumatic stress disorder (PTSD), the HPA axis is overactive [28], which has been associated with increased susceptibility to infectious diseases and cardiovascular problems. The HPA axis plays a significant role in homeostatic mechanisms involved in stress responses [29]. CORT is a hormonal end product of the HPA axis [30]. Changes in HPA-axis hormones vary among stimulus types and different varieties of rats, and can be used as an index of the intensity of a stressor [31, 32]. The human stress response is underpinned by core stress hormones, which involve the fast-acting autonomic nervous system (which triggers a noradrenergic response, leading to increased heart and respiration rates) and the slower acting HPA axis (which elicits a glucocorticoid response); this response then downregulates sympathetic arousal [33].

Exposure to stressful stimuli is associated with the activation of NOS and generation of NO [34]. NO plays a crucial role in the regulation of the central nervous system and endocrine function. The presence of NOS in hypothalamic nuclei, median bulges, and the pituitary gland is highly correlated with the regulation of pituitary activity [35]. Previous studies indicate that NO affects the activity of the HPA axis [36], and there is evidence that NO can affect the release of CRH through paracrine actions [37], thereby suggesting that after stress, endogenous NO production activates nNOS, possibly by affecting $\mathrm{CRH}$ and activating the HPA axis; this subsequently prompts endogenous production of CORT and catecholamines to resist stress. In this study, the results of western blotting and RT-PCR showed that the expressions of NO and nNOS were increased in the PVN of rats with transport stress, indicating endogenous nNOS activation to produce NO after transport stress.

The hypothalamus occupies the third ventricle on the ventral side and is located above the pituitary. Elevated HPA activity is associated with altered functions of the hypothalamus, pituitary, and gonads [38]. The hypothalamic PVN and SON are closely related to stress [39]. These areas can regulate water/salt balance, blood pressure, and metabolism with the secretion of vasopressin (VAS) and oxytocin (OXY). The activation of the HPA axis relies on the excitation of neuroendocrine neurons in the hypothalamic PVN that secrete CRH [40]. Among them, the hypothalamic PVN, which innervates the median ridge, is the most typical hypothalamic nucleus that secretes $\mathrm{CRH}$ and contains neurons that directly innervate the preganglionic autonomic and anterior pituitary. Therefore, the PVN plays a significant role in regulating hypothalamic stress, feeding, drinking behavior, and a series of autonomic responses [41, 42]. The PVN consists of large- and small-cell regions, and each branch has a sub-branch that contains a unique neurotransmitter distribution [43]. The hypothalamic PVN is a complete and unique part of the neuroendocrine system. Concerning structural function, the PVN can be divided into three main types of neurons: large neuroendocrine neurons, small neuroendocrine neurons, and descending neurons [44, 45]. Large neuroendocrine neurons are classified into VAS and OXY neurons. Small neuroendocrine neurons are divided into the neurons that synthesize and release $\mathrm{CRH}$, thyrotropinreleasing hormone (TRH), dopamine, somatostatin (SS), and gonadotropin-releasing hormone. Almost all of the neuroendocrine neurons that synthesize and release CRH and TRH in the brain are in the PVN, as are most SS endocrine neurons. Descending PVN neurons directly innervate the thalamus, brainstem, and spinal cord. In this study, the PVN was divided into four regions for analysis: the Paap, Pamm, Pav, and Palm. The results showed that nNOS-positive neurons in the control group were distributed in different regions of the PVN and were highly distributed in the ventral region and the lateral large cell region $(\mathrm{Pav}+\mathrm{Palm})$. Taken together, this study explored the effects of transport stress on nNOS expression in the hypothalamic PVN and the distribution of this morphology in rats. The findings from this study provide a basis for the investigation of the relationship among the hypothalamus, NO-nNOS, and the HPA axis. 


\section{Conclusions}

The current study used a rat model of simulated transport stress to investigate the effects of transport stress on nNOS expression in the rat brain, especially in regions related to stress responses, such as the hypothalamus. Physiological and psychological stress responses were successfully induced in rats subjected to simulated transport stress. Transport stress enhanced nNOS expression in the hypothalamus, indicating that nitrergic neurons in the hypothalamus are likely involved in transportation-induced stress, anxiety, and behavioral dysfunction.

\section{Abbreviations \\ CORT: Serum corticosterone; CRH: Corticotropin-releasing hormone; HPA: Hypothalamic-pituitary-adrenal; NE: Norepinephrine; nNOS: neuronal nitric oxide synthase; NO: Nitric oxide; PVN: Paraventricular nucleus; SON: Supraoptic nucleus}

\section{Acknowledgments}

We thank LetPub for its linguistic assistance during the preparation of this manuscript.

\section{Authors' contributions}

Study design: YM; data collection: MY and JW; statistical analysis: JW, JL and MY; manuscript preparation: JW and YM; administrative, technical, and material support: YM, JW, JL and YW. All the authors read, revised, and approved the final manuscript.

\section{Funding}

This work was sponsored by the National Natural Science Foundation of China (Nos. 31772686 and 31502025) and the Public Service Sectors Agriculture Research Projects of the Ministry of Agriculture of China (No. 201403051-07). The funding sources had no involvement in the design of the study, writing of the manuscript, in the collection, analysis, and interpretation of data.

\section{Availability of data and materials}

The data sets analyzed and used in the current study are available from the corresponding author upon reasonable request.

\section{Ethics approval}

All efforts were made to minimize suffering of each animal used in this study. All animal procedures conformed to the National Institutes of Health guidelines and were approved by the Institutional Animal Care and Use Committee of China Agricultural University.

\section{Consent for publication}

The authors declare that they consent for publication.

\section{Competing interests}

The authors declare that they have no competing interests.

Received: 17 April 2019 Accepted: 30 August 2019

Published online: 06 September 2019

\section{References}

1. Minka NS, Ayo JO. Physiological responses of food animals to road transportation stress. African J Biotechnol. 2010;8(25):6601-13.

2. Fazio E, Ferlazzo A. Evaluation of stress during transport. Vet Res Commun 2003;27(Suppl 1):519-24

3. Broom DM. Causes of poor welfare in large animals during transport. Vet Res Commun. 2003;27(Suppl 1):515-8

4. Warriss PD, Brown SN. A survey of mortality in slaughter pigs during transport and lairage. Vet Rec. 1994;134(20):513-5.

5. Kadim IT, Mahgoub O, Al-Marzooqi W, Khalafa S, Al-Sinawib SSH, Al-Amrib IS. Effects of transportation during the hot season and low voltage electrical stimulation on histochemical and meat quality characteristics of sheep longissimus muscle. Livest Sci. 2009;126(1-3):154-61.

6. Minka NS, Ayo JO. Effects of loading behaviour and road transport stress on traumatic injuries in cattle transported by road during the hot-dry season. Livest Sci. 2007;107(1):91-5.

7. Swallow J, Anderson D, Buckwell AC, Harris T, Hawkins P, Kirkwood J, Lomas M, Meacham S, Peters A, Prescott M, Owen S, Quest R, Sutcliffe R, Thompson K. Transport working group, laboratory animal science association (LASA). Guidance on the transport of laboratory animals. Lab Anim. 2005;39(1):1-39.

8. Fazio E, Medica P, Cravana C, Ferlazzo A. Cortisol response to road transport stress in calm and nervous stallions. J Vet Behav. 2013;8(4):231-7.

9. Mayer EA, Fanselow MS. Dissecting the components of the central response to stress. Nat Neurosci. 2003:6(10):1011-2.

10. Chen J, Tu Y, Moon C, Matarazzo V, Palmer AM, Ronnett GV. The localization of neuronal nitric oxide synthase may influence its role in neuronal precursor proliferation and synaptic maintenance. Dev Biol. 2004;269(1):165-82.

11. Jiang X, Mu D, Manabat C, Koshy AA, Christen S, Täuber MG, Vexler ZS, Ferriero DM. Differential vulnerability of immature murine neurons to oxygen-glucose deprivation. Exp Neurol. 2004;190(1):224-32.

12. Wang H, Kohr MJ, Traynham CJ, Wheeler DG, Janssen PM, Ziolo MT Neuronal nitric oxide synthase signaling within cardiac myocytes targets phospholamban. Am J Physiol Cell Physiol. 2008;294(6):C1566-75.

13. Yuan Z, Liu B, Yuan L, Zhang Y, Dong X, Lu J. Evidence of nuclear localization of neuronal nitric oxide synthase in cultured astrocytes of rats. Life Sci. 2004;74(26):3199-209.

14. Bredt DS, Snyder SH. Isolation of nitric oxide synthetase, a calmodulinrequiring enzyme. Proc Natl Acad Sci U S A. 1990;87(2):682-5.

15. Dinerman JL, Dawson TM, Schell MJ, Snowman A, Snyder SH. Endothelial nitric oxide synthase localized to hippocampal pyramidal cells: implications for synaptic plasticity. Proc Natl Acad Sci U S A. 1994;91(10):4214-8.

16. Stern JE. Nitric oxide and homeostatic control: an intercellular signalling molecule contributing to autonomic and neuroendocrine integration? Prog Biophys Mol Biol. 2004;84(2-3):197-215

17. Wan C, Yin P, Xu X, Liu M, He S, Song S, Liu F, Xu J. Effect of simulated transport stress on the rat small intestine: a morphological and gene expression study. Res Vet Sci. 2014:96(2):355-64

18. Zheng S, Zhu J, Li J, Zhang S, Ma Y. Leonurine protects ischemia-induced brain injury via modulating SOD, MDA and GABA levels. Front Agr Sci Eng. 2019;6(2):197-205

19. Wang L, Han D, Yin P, Teng K, Xu J, Ma Y. Decreased tryptophan hydroxylase 2 mRNA and protein expression, decreased brain serotonin concentrations, and anxiety-like behavioral changes in a rat model of simulated transport stress. Stress. 2019:11:1-11.

20. de Groot J. The rat hypothalamus in stereotaxic coordinates. J Comp Neurol. 1959:113:389-400.

21. Paxinos $G$, Watson $C$. The rat brain in stereotaxic coordinates. 6th ed. London: Academic; 2007.

22. Stokes WS. Reducing unrelieved pain and distress in laboratory animals using humane endpoints. ILAR J. 2000;41(2):59-61.

23. Obernier JA, Baldwin RL. Establishing an appropriate period of acclimatization following transportation of laboratory animals. ILAR J. 2006:47(4):364-9.

24. Armario A. The hypothalamic-pituitary-adrenal axis: what can it tell us about stressors? CNS Neurol Disord Drug Target. 2006:5(5):485-501.

25. Gaillard RC. Interaction between the hypothalamo-pituitary-adrenal axis and the immunological system. Ann Endocrinol (Paris). 2001:62(2):155-63.

26. Lo lacono L, Gross C. Alpha- $\mathrm{Ca}^{2+} /$ calmodulin-dependent protein kinase II contributes to the developmental programming of anxiety in serotonin receptor 1A knock-out mice. J Neurosci. 2008;28(24):6250-7.

27. Raison $\mathrm{CL}$, Miller $\mathrm{AH}$. When not enough is too much: the role of insufficient glucocorticoid signaling in the pathophysiology of stress-related disorders. Am J Psychiatry. 2003;160(9):1554-65

28. Ehlert U, Gaab J, Heinrichs M. Psychoneuroendocrinological contributions to the etiology of depression, posttraumatic stress disorder, and stress-related bodily disorders: the role of the hypothalamus-pituitary-adrenal axis. Biol Psychol. 2001;57(1-3):141-52

29. Fazio E, Medica P, Cravana C, Ferlazzo AA. Pituitary-adrenocortical adjustments to transport stress in horses with previous different handling and transport conditions. Vet World. 2016:9(8):856-61.

30. Herman JP, Ostrander MM, Mueller NK, Figueiredo H. Limbic system mechanisms of stress regulation: hypothalamo-pituitary-adrenocortical axis. Prog Neuro-Psychopharmacol Biol Psychiatry. 2005;29(8):1201-13. 
31. McEwen BS. The neurobiology of stress: from serendipity to clinical relevance. Brain Res. 2000;886(1-2):172-89.

32. Wood GE, Young $L T$, Reagan $L P, M c E w e n$ BS. Acute and chronic restraint stress alter the incidence of social conflict in male rats. Horm Behav. 2003:43(1):205-13.

33. Tsigos C, Chrousos GP. Hypothalamic-pituitary-adrenal axis, neuroendocrine factors and stress. J Psychosom Res. 2002;53(4):865-71.

34. Kumar A, Chanana P. Role of nitric oxide in stress-induced anxiety: from pathophysiology to therapeutic target. Vitam Horm. 2017;103:147-67.

35. Kim CK, Rivier C. Influence of nitric oxide synthase inhibitors on the ACTH and cytokine responses to peripheral immune signals. J Neuroendocrinol. 1998;10(5):353-62.

36. Joung HY, Jung EY, Kim K, Lee MS, Her S, Shim I. The differential role of NOS inhibitors on stress-induced anxiety and neuroendocrine alterations in the rat. Behav Brain Res. 2012;235(2):176-81.

37. Costa A, Trainer P, Besser M, Grossman A. Nitric oxide modulates the release of corticotropin-releasing hormone from the rat hypothalamus in vitro. Brain Res. 1993;605(2):187-92.

38. Joseph DN, Whirledge S. Stress and the HPA axis: balancing homeostasis and fertility. Int J Mol Sci. 2017;18(11):2224.

39. Badowska-Szalewska E, Ludkiewicz B, Krawczyk R, Morys J. Exposure to mild stress and brain derived neurotrophin factor (BDNF) immunoreactivity in the hypothalamic paraventricular (PVN) and supraoptic (SON) nuclei: comparison between aged and adult rats. J Chem Neuroanat. 2016;78:57-64.

40. Salter EW, Sunstrum JK, Matovic S, Inoue W. Chronic stress dampens excitatory synaptic gain in the paraventricular nucleus of the hypothalamus. J Physiol. 2018;596(17):4157-72.

41. Elmquist JK, Elias CF, Saper CB. From lesions to leptin: hypothalamic control of food intake and body weight. Neuron. 1999;22(2):221-32.

42. Loewy AD. Forebrain nuclei involved in autonomic control. Prog Brain Res. 1991:87:253-68.

43. Armstrong WE, Warach $\mathrm{S}$, Hatton $\mathrm{Gl}$, McNeill TH. Subnuclei in the rat hypothalamic paraventricular nucleus: a cytoarchitectural, horseradish peroxidase and immunocytochemical analysis. Neuroscience. 1980;5(11):1931-58.

44. Swanson LW. Biochemical switching in hypothalamic circuits mediating responses to stress. Prog Brain Res. 1991;87:181-200.

45. Swanson LW. Spatiotemporal patterns of transcription factor gene expression accompanying the development and plasticity of cell phenotypes in the neuroendocrine system. Prog Brain Res. 1992;92:97-113.

\section{Publisher's Note}

Springer Nature remains neutral with regard to jurisdictional claims in published maps and institutional affiliations.

Ready to submit your research? Choose BMC and benefit from:

- fast, convenient online submission

- thorough peer review by experienced researchers in your field

- rapid publication on acceptance

- support for research data, including large and complex data types

- gold Open Access which fosters wider collaboration and increased citations

- maximum visibility for your research: over $100 \mathrm{M}$ website views per year

At BMC, research is always in progress.

Learn more biomedcentral.com/submissions 